\title{
KAJIAN NILAI KOEFISIEN HAMBAT PADA SALURAN TERBUKA
}

\author{
Cahya Sujatmiko \\ Dosen Fakultas Teknik Universitas Saburai
}

\begin{abstract}
Open channel flow is the natural phenomenon that research by hydraulic engineer. Roughness of the channel is the drag factor of the flow and the value depend on the roughness caracteristics. Chezy coefficient is the coefficient of flow equation determining velocity at the channel. The value of the chezy coefficient is depend of flow caracteristics and roughness of the channel. Research target conducted to learn the value of the chezy coefficient and drag coefficient at the open channel flow with the cylindrical roughness and determine the parameter having an effect on and also relation usher the parameter. The result of cylindrical will be application to the flow with the resistance grow on mangrove. This research used 6 vertical bar model by 6 variation of density to 2 vertical bar diameter. Simulation model the vertical bar conducted by 4 variation of discharge the stream range from 0,00825 until $0,01374 \mathrm{~m} / \mathrm{s}$ and 5 variation of stream deepness by turning around back door (tail gate). Scale model $1: 10$ used to support the measurement correctness beside consideration of equipments limitation. Research data analysis use the way of comparison between theoretical with the research to yield the relation of non dimensionaless. Result of this research indicate that ever greater of density, depth flow and diameter of cylindrical hence yielded chezy coefficient smaller that mean drag flow is greater. Chezy coefficient yielded range 3,82 $10,579 \mathrm{~m} / 2 / \mathrm{s}$ with the density range $0,498-6,883$ while drag coefficient value result of average 0,95. Average velocity for cylindrical roughness can be determine with the equation of Chezy, $C=\sqrt{\frac{g \cdot \pi \cdot D}{C_{D} \cdot 2 \cdot \xi \cdot h}}$.
\end{abstract}

Keywords : chezy coefficient, cylindrical, flow, drag coefficient

\section{PENDAHULUAN}

Saluran terbuka memiliki berbagai macam karakteristik bila dihubungkan dengan aliran, salah satunya adalah hambatan pada aliran. Penelitian tentang hambatan telah banyak dilakukan oleh para ahli hidrolik antara lain Darcy-Weisbach, Chezy dan Manning. Sedangkan untuk aliran dengan kekasaran telah diteliti ahli hidrolik seperti Powell, Morris, Sayre, Albertson, Chen dan Taylor. Lebih khusus lagi aliran dengan kekasaran tumbuh-tumbuhan telah diteliti oleh Wessels, Strelkoff, $\mathrm{Li}$, dan Shen dalam Stone dan Shen (2002).
Memahami aliran dengan hambatan menjadi sesuatu hal yang paling mendasar sebagai pengetahuan yang diperlukan bagi insinyur hidrolik untuk menentukan karakteristik debit pada aliran. Salah satu cara untuk memahami hambatan pada aliran yaitu dengan menggunakan kekasaran batang vertikal yang ditempatkan pada aliran saluran terbuka.

Penelitian ini dilakukan dengan tujuan untuk mempelajari nilai koefisien hambat pada aliran saluran terbuka dengan hambatan batang vertikal bulat dan menentukan parameter yang berpengaruh serta hubungan antar parameter tersebut. 
Hasil penelitian diharapkan dapat menjadi kajian yang berguna bagi penelitian selanjutnya.

\section{TINJAUAN PUSTAKA}

Persamaan Chezy merupakan persamaan untuk aliran dan dirumuskan oleh Antonie Chezy dinyatakan sebagai

$V=C \sqrt{R S}$

dengan $V$ kecepatan rata-rata dalam meter kubik per detik, $R$ jari-jari hidrolik dalam meter, $S$ kemiringan saluran dan $C$ faktor tahanan aliran yang disebut faktor $C$ dari Chezy.

Beberapa percobaan yang telah dilakukan untuk menentukan nilai koefisien Chezy (C) diantaranya ada empat yaitu a) Ganguillet-Kutter, b) Bazin, c) Powell, dan d) Manning.

Yuwono

menghubungkan koefisien chezy dengan faktor kedalaman dan kekasaran pada dasar saluran terbuka

$C=18 \log \frac{12 h}{k}$

dengan $C$ koefisien chezy $\left(\mathrm{m}^{1 / 2} / \mathrm{det}\right)$, $h$ kedalaman aliran $(\mathrm{m}), k$ kekasaran dasar (m).

Tegangan geser $(\tau)$ dapat dianggap konstan terhadap batas keseluruhan saluran. Dengan menganggap aliran adalah seragam, maka tegangan geser pada saluran adalah

$\tau=\rho \cdot g \cdot R \cdot S$

Bila tegangan geser ini dihubungkan dengan koefisien chezy yaitu menggabungkan persamaan 1 dan 3 maka akan didapatkan $\tau=\frac{\rho \cdot g \cdot V^{2}}{C^{2}}$

Tegangan geser pada saluran terbuka dengan aliran terhambat batang vertikal dapat dibagi menjadi 2 (lihat Gambar 1) yaitu : a). Tegangan geser dasar saluran, dan b). Tegangan geser batang vertikal.

$\tau_{0}=\tau_{1}+\tau_{2}$

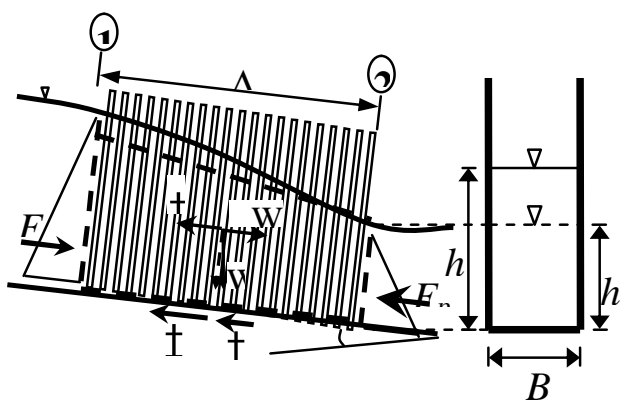

Gambar 1 Aliran pada saluran persegi empat dengan hambatan batang vertikal

Tegangan geser dasar saluran tanpa batang vertikal adalah

$\tau_{1}=\frac{\rho \cdot V^{2}}{C_{1}^{2}}$

Tegangan geser pada kelompok batang vertikal adalah

$\tau_{2}=C_{D} \cdot \rho \cdot n \cdot h \cdot D \cdot \frac{v^{2}}{2}$

Persamaan 6 dan 7 disubstisutikan ke Persamaan 5 didapatkan

$$
C_{0}^{2}=\frac{1}{\frac{1}{C_{1}^{2}}+\frac{C_{D} \cdot n \cdot h \cdot D}{2 g}}
$$

Kerapatan adalah perbandingan antara volume batang vertikal yang terendam air dengan volume total air pada daerah batang vertikal yang merendamnya. 
$\xi=\frac{V_{B}}{V_{T}}$

$\xi=\frac{\text { Volume batang vertikal yang terendam air }}{\text { Volume total air pada daerah batang vertikal }} \times 100 \%$

$\xi=n \cdot A \times 100 \%$

Disebabkan bentuknya yang bulat maka Persamaan 10 menjadi

$\xi=\frac{n \cdot \pi \cdot D^{2}}{4} \times 100 \%$

Dari Persamaan 8 akan didapatkan persamaan koefisien hambat $\left(C_{D}\right)$ untuk aliran dengan hambatan batang vertikal dan pengaruh kekasaran dasar saluran.

$C_{D}=\frac{2 g}{n \cdot h \cdot D}\left(\frac{1}{C_{0}^{2}}-\frac{1}{C_{1}^{2}}\right)$

$$
\text { Jika persamaan }
$$

disubstitusikan ke Persamaan 12 maka didapatkan

$$
C_{D}=\frac{g \cdot \mathrm{D} \cdot \pi}{2 \cdot \xi \cdot h}\left(\frac{1}{C_{0}^{2}}-\frac{1}{C_{1}^{2}}\right)
$$

$$
\text { Dengan menggunakan }
$$

Persamaan 13, didapatkan persamaan koefisien chezy

$$
C_{0}=\sqrt{\frac{1}{\frac{C_{D} \cdot 2 \cdot \xi \cdot h}{g \cdot \pi \cdot \mathrm{D}}+\frac{1}{C_{1}^{2}}}}
$$

Jika menganggap kekasaran dasar pengaruhnya kecil maka koefisien chezy $\left(C_{1}\right)$ dapat diabaikan sehingga persamaan 14 akan menjadi

$$
C_{0}=\sqrt{\frac{g \cdot \pi \cdot \mathrm{D}}{C_{D} \cdot 2 \cdot \xi \cdot h}}
$$

Koefisien hambat $\left(\mathrm{C}_{\mathrm{D}}\right)$ tanpa dipengaruhi kekasaran dasar adalah

$$
C_{D}=\frac{g \cdot \pi \cdot \mathrm{D}}{C_{0}^{2} \cdot 2 \cdot \xi \cdot h}
$$

Bilangan tak berdimensi digunakan untuk menyatakan hubungan antar parameter serta dipakai untuk menggambarkan hasilhasil penelitian dan dapat ditentukan bentuk hubungan diantaranya. Pertama kali diperkirakan parameterparameter fisik yang mempengaruhi aliran dan kemudian parameterparameter tersebut dikelompokkan dalam suatu bentuk tak berdimensi sehingga akhirnya dapat ditetapkan fenomena aliran yang lebih baik (Triatmodjo, 2003). Analisis dimensi menggunakan metode Buckingham didapatkan koefisien chezy tak berdimensi

$C_{c}=\frac{C_{0}}{\sqrt{g}}(17)$

dengan $C_{0}$ koefisien chezy ( $\mathrm{m}^{1 / 2} /$ det$)$, $g$ percepatan gravitasi $\left(\mathrm{m} / \mathrm{det}^{2}\right), C_{c}$ koefisien chezy tak berdimensi.

Persamaan koefisien chezy dengan kekasaran batang vertikal dijadikan bilangan tak berdimensi dengan memasukkan persamaan 17 ke persamaan 13, 14, 15 dan 16 didapatkan

$$
\begin{aligned}
& C_{c 1}=\sqrt{\frac{\frac{1}{C_{D} \cdot 2 \cdot \xi \cdot h}}{\pi \cdot \mathrm{D}}+\frac{1}{C_{1}^{2} \cdot g}} \\
& C_{D 1}=\frac{\pi \cdot \mathrm{D}}{2 \cdot \xi \cdot h}\left(\frac{1}{C_{c}^{2}}-\frac{1}{C_{1}^{2} \cdot g}\right) \\
& C_{c}=\sqrt{\frac{\pi \cdot \mathrm{D}}{C_{D} \cdot 2 \cdot \xi \cdot h}} \\
& C_{D}=\frac{\pi \cdot \mathrm{D}}{C_{c}^{2} \cdot 2 \cdot \xi \cdot h}
\end{aligned}
$$

\section{METODE PENELITIAN}

Penelitian dilaksanakan di Laboratorium Hidraulika dan Hidrologi, Pusat Studi Ilmu Teknik Universitas Gadjah Mada Yogyakarta. Pengambilan data dilakukan dengan mengamati perubahan kedalaman 
aliran pada sebelum dan sesudah model yang dipasang pada Standar Tilting Flume.

Model dibuat dari besi dan aluminium dengan dasar menggunakan multiplek setebal 18 $\mathrm{mm}$. Model terdiri dari 2 macam yaitu model batang vertikal dan model akar bakau. Model batang vertikal ada 2 variasi diameter yaitu $3,18 \mathrm{~mm}$ dan $12,7 \mathrm{~mm}$. Variasi kerapatan ada 6 yaitu 0,497\%, $1,032 \%, 1,959 \%, 1,942 \%, 3,843 \% \quad$ dan $6,883 \%$. Sedangkan model akar bakau terdiri dari 3 variasi kerapatan yaitu $1,023 \%, \quad 1,6567 \%$ dan $2,78 \%$ serta diameter akar 3,18 $\mathrm{mm}$ dan diameter batang $5 \mathrm{~mm}$. Model di susun secara teratur sehingga sebarannya merata dengan lebar model $30 \mathrm{~cm}$ dan panjang model $100 \mathrm{~cm}$.

Simulasi model dilakukan dengan 4 variasi debit dan 5 variasi kedalaman. Besaran debit berkisar antara 0,00825 sampai dengan 0,01374 $\mathrm{m}^{3} /$ det. Variasi kedalaman aliran sebelum dan sesudah model berkisar antara $10 \mathrm{~cm}$ sampai dengan $26 \mathrm{~cm}$.

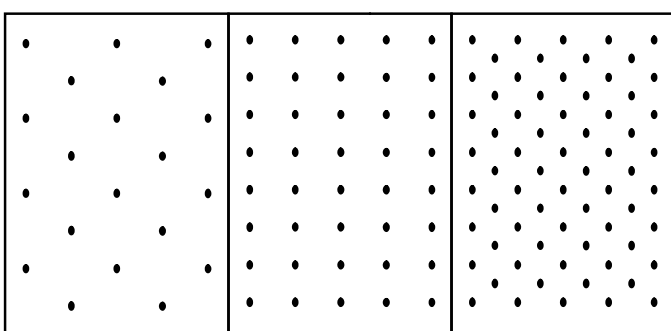

(a) (c)

Gambar 2 Variasi susunan batang vertikal (tampak atas)

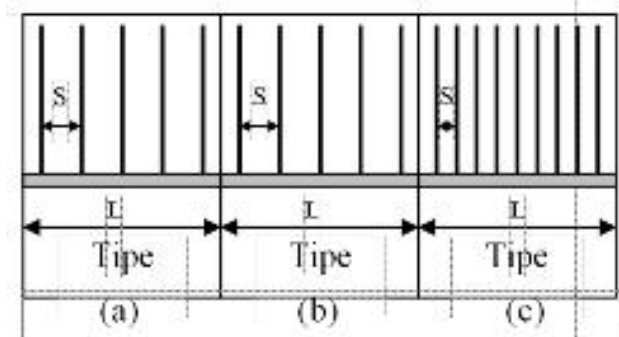

Gambar 3 Model batang vertikal (tampak samping) untuk setiap tipe model

\section{HASIL PENELITIAN DAN PEMBAHASAN}

Perhitungan Koefisien Chezy menggunakan persamaan 1 yang didapat dari penelitian selanjutnya dijadikan Koefisien Chezy tak berdimensi menggunakan persamaan 20. Koefisien Chezy tak berdimensi dihubungkan dengan parameter tak berdimensi $(\xi \cdot h / D)$ garis hubungan sebagaimana terlihat pada Gambar 6.

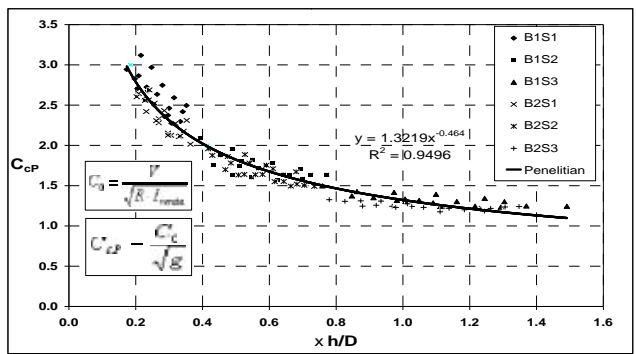

Gambar 6 Hubungan Koefisien Chezy tak berdimensi penelitian $\left(C_{c P}\right)$

$$
\text { dengan }(\xi \cdot h / D)
$$




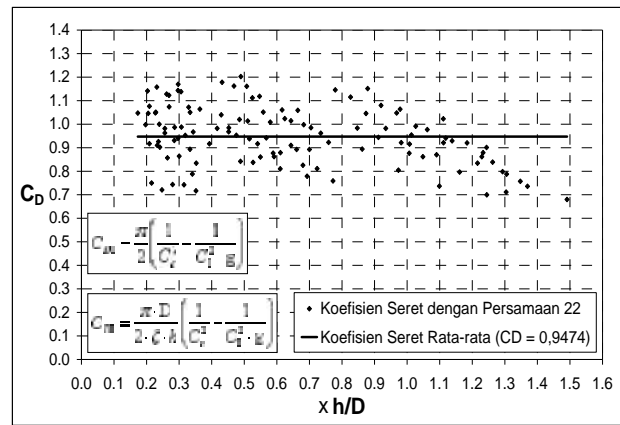

Gambar 7 Koefisien Hambat $\left(C_{D}\right)$ dengan $(\xi \cdot h / D)$ dipengaruhi kekasaran dasar

Hubungan Koefisien Hambat $\left(C_{D}\right)$ dengan parameter tak berdimensi $(\xi \cdot h / D)$ dengan kekasaran dasar saluran (persamaan 22) dan tanpa kekasaran dasar (persamaan 24).

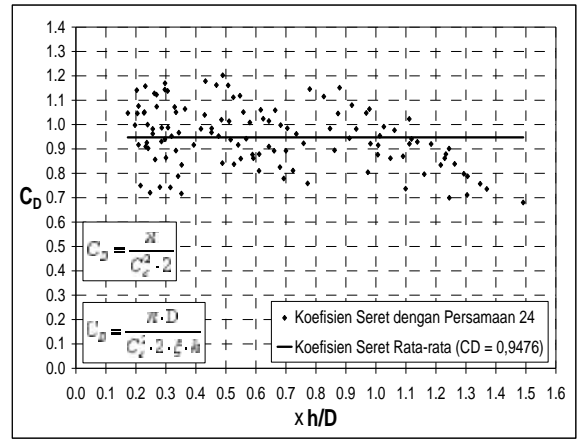

Gambar 8 Koefisien Hambat $\left(C_{D}\right)$ dengan ( $\xi \cdot h / D)$ tanpa kekasaran dasar saluran

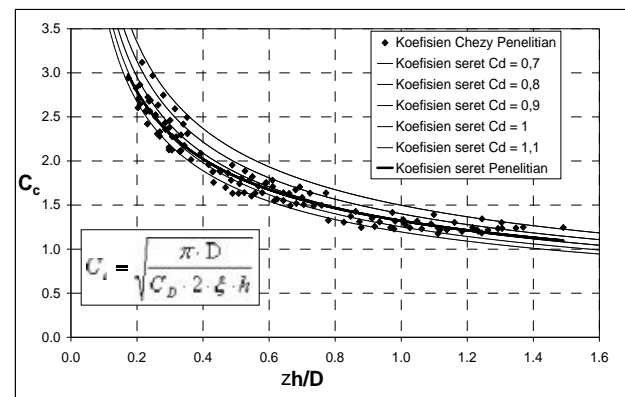

Gambar 9 Hubungan koefisien chezy tak berdimensi $\left(C_{c}\right)$ dengan parameter tak berdimensi $(\xi \cdot h / D)$ untuk variasi koefisien hambat $\left(C_{D}\right)$

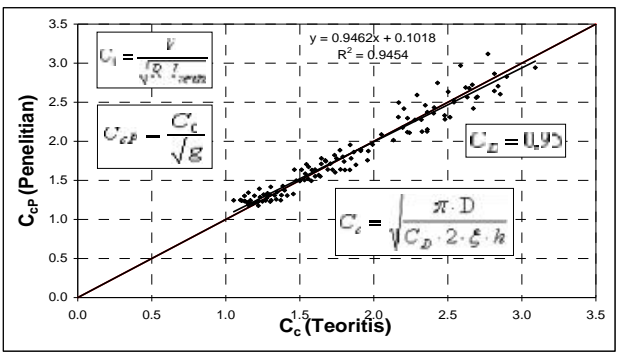

Gambar 10 Perbandingan Koefisien Chezy tak berdimensi $(C c)$ antara penelitian dengan teoritis untuk koefisien hambat $\left(C_{D}=0,95\right)$

Koefisien hambat rata-rata persamaan 22 dan persamaan 24 adalah 0,9474 dan 0,9476 sehingga dapat disimpulkan kekasaran dasar pengaruhnya kecil dan dapat diabaikan. Dengan menggunakan persamaan 24 didapatkan hubungan koefisien chezy tak berdimensi $\left(C_{c}\right)$ dengan parameter tak berdimensi ( $\xi \cdot h / D)$

Untuk koefisien hambat 0,7 sampai 1,1. Gambar 9 memperlihatkan koefisien hambat yang paling mendekati dengan hasil dari penelitian adalah garis antara 0,9 dan 1 Menggunakan metode perbandingan koefisien chezy tak berdimensi $\left(C_{c}\right.$ ) antara penelitian dengan teoritis didapatkan bahwa koefisien hambat yang mendekati garis hubungan adalah koefisien hambat 0,95 sebagaimana terlihat pada Gambar 10.

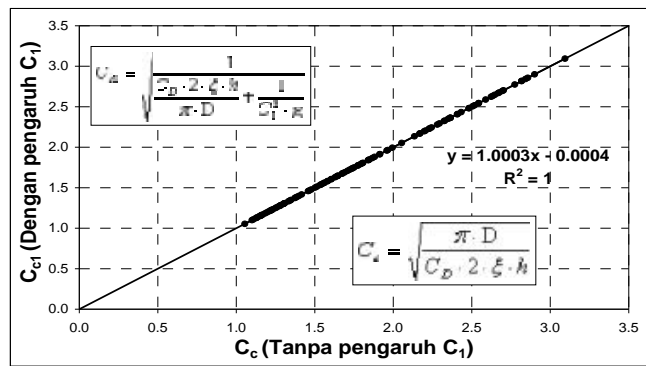


Gambar 11 Perbandingan koefisien chezy tak berdimensi $\left(C_{c}\right.$ ) dengan pengaruh kekasaran dasar

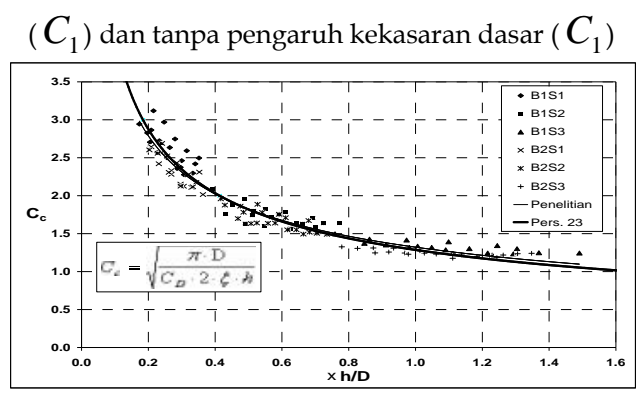

Gambar : 12 Koefisien chezy tak berdimensi

Gambar 12 Koefisien chezy tak berdimensi $\left(C_{c}\right)$ antara penelitian dan teoritis Perbandingan koefisien chezy tak berdimensi $\left(C_{c}\right)$ yang dipengaruhi kekasaran dasar saluran dengan tanpa kekasaran dasar didapatkan hasil sebagaimana terlihat pada Gambar 11. Hasil ini menjelaskan bahwa dengan angka korelasi $R^{2}=1$ dan garis yang dekat dengan garis perbandingan maka dapat disimpulkan kekasaran dasar saluran tidak berpengaruh dan selanjutnya dapat diabaikan.

Persamaan 24 dengan menggunakan koefisien hambat 0,95 maka dapat dibandingkan antara koefisien chezy tak berdimensi $\left(C_{c}\right)$ antara penelitian dengan teoritis (lihat Gambar 12). Hasil ini memperlihatkan bahwa persamaan 24 dapat digunakan untuk menghitung koefisien chezy pada aliran dengan hambatan batang vertikal.

\section{SIMPULAN}

1. Koefisien chezy pada aliran terhambat batang vertikal dipengaruhi oleh beberapa parameter yaitu kerapatan batang, kedalaman aliran, dan diameter batang. Bila nilai parameter ( $\xi \cdot h / D) \quad$ meningkat maka koefisien chezy akan menurun, hal ini membuktikan bahwa semakin besar hambatan pada aliran.

2. Koefisien chezy batang vertikal didapatkan hasil antara 3,82 $10,579 \mathrm{~m}^{1 / 2} /$ det dengan kerapatan antara 0,498 - 6,883. Hasil ini memperlihatkan bahwa semakin besar kerapatan maka nilai koefisien chezy akan semakin kecil.

3. Kekasaran dasar saluran pengaruhnya kecil sehingga dapat diabaikan.

4. Koefisien hambat untuk kelompok batang vertikal didapatkan 0,95. Nilai ini lebih kecil dari koefisien hambat untuk batang tunggal yaitu 1,2.

5. Persamaan 20 dapat digunakan untuk menghitung koefisien chezy pada aliran dengan hambatan batang vertikal.

\section{UCAPAN TERIMA KASIH}

Penulis mengucapkan terima kasih kepada Bapak Prof. Ir. Nur Yuwono, Dip.HE., Ph.D dan Bapak Ir. Radianta Triatmadja, Ph.D., yang telah memberikan bimbingan dan saransaran dalam penelitian ini. Kepada seluruh karyawan Laboratorium Hidraulika dan Hidrologi Pusat Studi Ilmu Teknik Universitas Gadjah Mada dan semua pihak yang telah membantu terlaksananya penelitian ini, penulis mengucapkan terima kasih. 


\section{DAFTAR PUSTAKA}

Chow, V.T., 1997, Hidraulika Saluran Terbuka (Open Channel Hydraulics), Penerbit Erlangga, Jakarta.

Novek P. and Cabelka J. 1981, Model in Hydraulic Engineering, Physical Principles and Design Applications, Pitman Publishing, London.

Stone B.M. and Shen H.T., 2002, HydraulicResistance of Flow in Channels with Cylindrical Roughness, Journal of Hydraulic Engineering ASCE, 128(5), 500 506.

Sujatmiko C., 2004, Equivalensi Nilai Koefisien Chezy Pada Aliran Terhambat Batang Vertikal, Tesis, Sekolah Pascasarjana UGM, Yogyakarta.
Triatmodjo B., 2003, Hiraulika II, Edisi kedua, Penerbit Beta Offset, Yogyakarta.

Triatmadja R. dan Sulistyawati S., 2001, Petunjuk Praktikum Mekanika Fluida dan Hidraulika, PAU-IT UGM - Jurusan Sipil UNS - Tamara Overseas Corp., Yogyakarta. Wu F.C, Shen H.W. and Chou Y.J., 1999, Variation of Roughness Coefficients for Unsubmerged and Submerged Vegetation, Journal of Hydraulic Engineering ASCE, 125(8), 934 942

Yuwono N., 1996, Perencanaan Model Hidraulik (Hydraulic Modelling), Lab. Hidrolika dan Hidrologi, PAU IT UGM, Yogyakarta. 